\title{
A protocol for assessing the effectiveness of oil spill dispersants in stimulating the biodegradation of oil
}

\author{
Roger C. Prince • Josh D. Butler
}

Received: 30 May 2013 / Accepted: 31 July 2013 /Published online: 13 August 2013

(C) The Author(s) 2013. This article is published with open access at Springerlink.com

\begin{abstract}
Dispersants are important tools in oil spill response. Taking advantage of the energy in even small waves, they disperse floating oil slicks into tiny droplets $(<70 \mu \mathrm{m})$ that entrain in the water column and drift apart so that they do not re-agglomerate to re-form a floating slick. The dramatically increased surface area allows microbial access to much more of the oil, and diffusion and dilution lead to oil concentrations where natural background levels of biologically available oxygen, nitrogen, and phosphorus are sufficient for microbial growth and oil consumption. Dispersants are only used on substantial spills in relatively deep water (usually $>10 \mathrm{~m}$ ), conditions that are impossible to replicate in the laboratory. To date, laboratory experiments aimed at following the biodegradation of dispersed oil usually show only minimal stimulation of the rate of biodegradation, but principally because the oil in these experiments disperses fairly effectively without dispersant. What is needed is a test protocol that allows comparison between an untreated slick that remains on the water surface during the entire biodegradation study and dispersant-treated oil that remains in the water column as small dispersed oil droplets. We show here that when this is accomplished, the rate of biodegradation is dramatically stimulated by an effective dispersant, Corexit $9500^{\circledR}$. Further development of this approach might result in a useful tool for comparing the full benefits of different dispersants.
\end{abstract}

Keywords Oil spill dispersants · Crude oil · Biodegradation · Oil spill response

Responsible editor: Robert Duran

R. C. Prince $(\bowtie) \cdot$ J. D. Butler

ExxonMobil Biomedical Sciences, Inc., Annandale, NJ 08801, USA

e-mail: roger.c.prince@exxonmobil.com

\section{Introduction}

Dispersants are important options in the "tool box" for responding to marine oil spills. Developed after initial attempts to disperse oil with simple industrial cleaners (National Research Council 1989), current products are carefully blended mixtures of usually food-grade surfactants and solvents (National Research Council 2005) that can disperse a range of crude oils and refined products (Lessard and DeMarco 2000) over a wide range of conditions ranging from arctic (Belore et al. 2009) to tropical (Zahed et al. 2011).

Several laboratory protocols have been developed for testing the relative efficacy of different dispersants: the air current test (Mackay et al. 1978), the Warren Springs rolling flask test (Martinelli 1984), the swirling flask test (Clayton et al. 1993), the Exxon dispersant effectiveness test (Becker et al. 1993), and the baffled flask test (Venosa et al. 2002) among others. Comparisons of these tests with field and tank data have been reported by Clark et al. (2005), and the baffled flask test was used to compare eight potential dispersants during the response to the Deepwater Horizon spill (Venosa and Holder 2012).

Useful as they are, these are very small volume tests, and they are not amenable to studying long-term processes (days to weeks) such as biodegradation. In practice, dispersants are only used on significant slicks, and the tests use relatively high concentrations of oil to mimic this. In the field, the dispersed oil droplets (typically $<70 \mu \mathrm{m}$ ) diffuse apart, dropping to concentrations below $1 \mathrm{ppm}$ in hours to days (Delvigne 1993; Li et al. 2009; Lee et al. 2013), and they do not re-coalesce. Until now, laboratory tests have used volumes that keep the oil concentration in the many hundreds to many thousands of parts per million, and re-coalescence occurs in hours to days.

The ultimate purpose of oil spill dispersants is to dilute spilled oil so that indigenous microbes in the sea can consume the oil. Hydrocarbons are excellent sources of carbon and energy for those organisms, prokaryotic (Prince et al. 2010) 


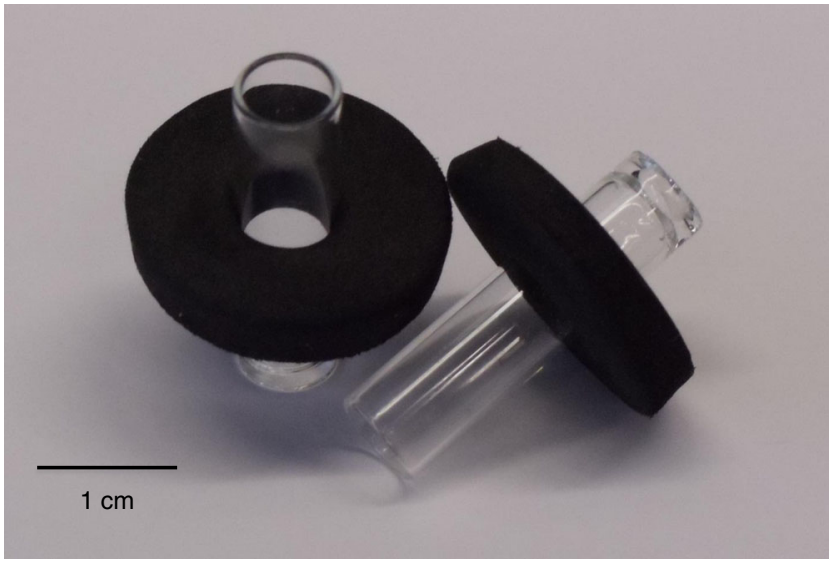

Fig. 1 Glass "booms" to maintain small volumes of oil as a floating slick. The thin glass tubing is held upright by the closed cell ethylene vinyl acetate foam

and eukaryotic (Prince 2010), able to initiate biodegradation, but they lack biologically available nitrogen, phosphorus, and other essential elements for microbial growth. Fortunately, seawater usually provides enough of these nutrients if the hydrocarbons are in the few parts per million concentration or less, and biodegradation of dilute oil has a "half-life" of days to weeks (Hazen et al. 2010; Baelum et al. 2012; Prince et al. 2013).

Quantitatively demonstrating that oil dispersants do indeed stimulate oil biodegradation under controlled conditions has been a major challenge. Current protocols for testing the efficacy of dispersants generate dispersions that are far too concentrated for the available nitrogen, phosphorus, etc. in seawater to allow prompt biodegradation, and experiments are rarely carried out long enough for biodegradation to occur even if the nutrient problem is overcome by adding fertilizer (although see MacNaughton et al. 2003). Conversely, oil at the few parts per million level, where biodegradation is rapid, is dispersed fairly well by laboratory stirring even without adding dispersants, and dispersants have only a minimal stimulatory effect on biodegradation (Prince et al. 2013). Here, we describe experiments where the total oil available in the system is dilute enough that there are potentially enough nutrients in the seawater for rapid biodegradation, but where natural dispersion is slowed by enclosure of the oil in a floating boom unless dispersant is added. These concentrations approximate those found after the successful application of dispersants at sea (Lee et al. 2013), and are below levels where any measurable toxicity occurs, even in 48 (Americamysis bahia) or $96 \mathrm{~h}$ (Menidia beryllina) tests (Hemmer et al. 2011). Under these conditions, Corexit 9500, the dispersant used most widely following the Deepwater Horizon spill, dramatically stimulates the rate of oil biodegradation.

\section{Methods}

Seawater was collected from the New Jersey shore in August and September, 2012 (summer conditions; salinity $=28 \mathrm{ppt}$, temperature $=21^{\circ} \mathrm{C}$ ). Nitrate and phosphate levels were below detection limits with simple laboratory colorimetric tests, but are likely to have been near 7 and $0.5 \mu \mathrm{M}$, respectively (Louanchi and Najjar 2001). The experiments used 41 of this seawater in 51 carboys, maintained at $21{ }^{\circ} \mathrm{C}$ in a growth chamber with a diurnal light cycle ( $16 \mathrm{~h}$ on, $8 \mathrm{~h}$ off). The oil was Alaska North Slope crude (ExxonMobil 2013), weathered by evaporation at laboratory room temperature in a hood
Fig. 2 Total ion chromatograms of the oils (without and with dispersant added at a dispersant to oil ratio of 1:15) extracted after 15 min (initial), 7 and 14 days. The "booms" were removed from the experimental vessels, separated from their flotation collars, and extracted with methylene chloride, as was the water phase. No detectable hydrocarbons were found in the water phase of the oil without dispersant, and none on the glass boom in the samples with dispersant
$20 \%$ weathered oil as slick

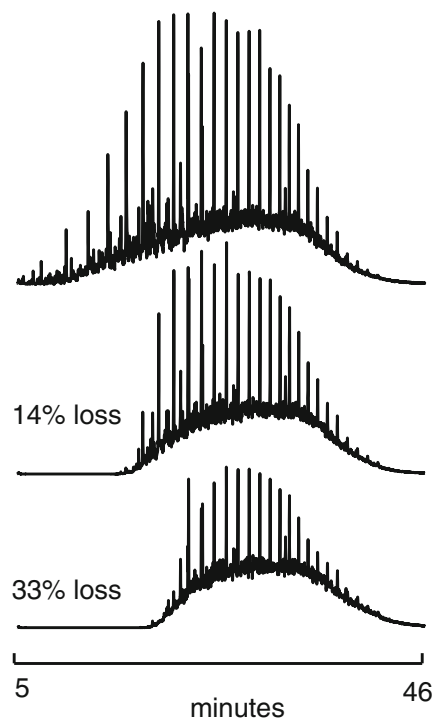

$20 \%$ weathered oil with dispersant $15: 1$

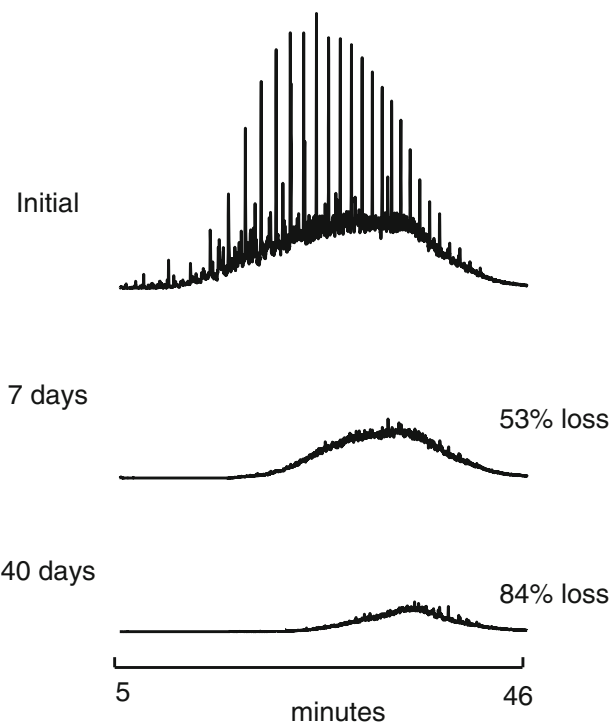


Fig. 3 Loss of a total detectable hydrocarbons and $\mathbf{b}$ the sum of the USEPA priority pollutants (Keith and Telliard 1979) from samples with and without dispersant a

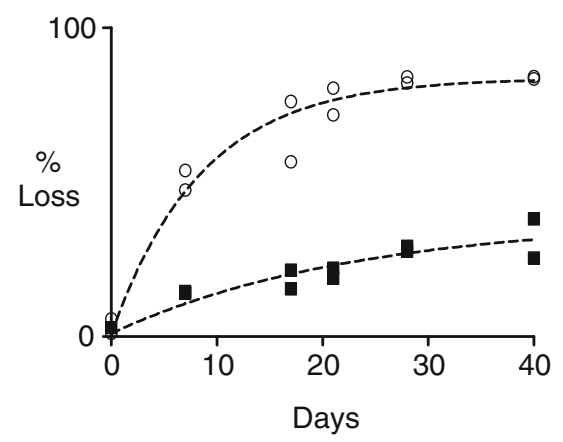

b

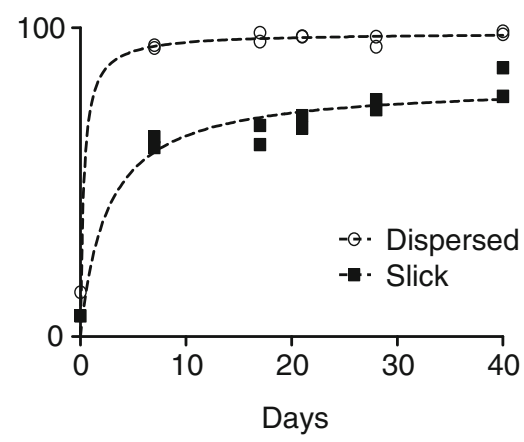

until it had lost $20 \%$ of its weight; this is a reasonable simulacrum of oil that has weathered between a spill and the application of dispersant from the air (National Research Council 1989, 2005). Oil (10 $\mu$ l) was added into small floating booms (Fig. 1), some receiving oil alone, others receiving oil that had been premixed with Corexit 9500 at a dispersant to oil ratio of $1: 15$. The glass booms enclosed a surface area of $28 \mathrm{~mm}^{2}$, so the $10 \mu \mathrm{l}$ resulted in a slick with a nominal thickness of $350 \mu \mathrm{m}$, although of course there was a meniscus around the edge. The vessels were stirred with a magnetic stirrer to generate a 2-cm vortex, and within minutes, the oil with dispersant had dispersed into the water (to a nominal concentration of $2.5 \mathrm{ppm}$ ), while the oil without dispersant remained in the boom. Carboys were incubated up to 40 days, with duplicate vessels with and without dispersant sacrificed at various times throughout the study.
Upon sacrifice, the booms were carefully removed and the carboys extracted three times with methylene chloride. The glass booms were removed from their foam flotation collars and washed twice with methylene chloride. The methylene chloride extracts were collected with a pipette, evaporated carefully to a few milliliters, dried over anhydrous sodium sulfate, and then evaporated to approximately $1 \mathrm{ml}$, with care to prevent concentration to dryness. In the absence of dispersant, there were no detectable hydrocarbons in the bulk phase, while with dispersant, there was no oil remaining on the glass booms.

Oils were analyzed by gas chromatography coupled with mass spectrometry (Douglas et al. 1992). Hydrocarbon biodegradation was followed with respect to $17 \alpha(\mathrm{H}), 21 \beta(\mathrm{H})-$ hopane as a conserved internal marker within the oil (Prince et al. 1994).
Fig. 4 Loss of naphthalene, phenanthrene, and their alkylated congeners from samples with and without dispersant. $N$ indicates naphthalene, $C 1 N$ indicates the sum of the methylnaphthalenes, $C 2 N$ indicates the sum of the dimethyl- and ethyl-naphthalenes, $C 3 N$ the sum of the trimethyl-, methylethyl-, propyl-, and isopropyl-naphthalenes, etc., while $P$ indicates phenanthrene, etc. We detected no significant preferences for the biodegradation of any isomers over others

\section{Slick}

\section{Naphthalenes}
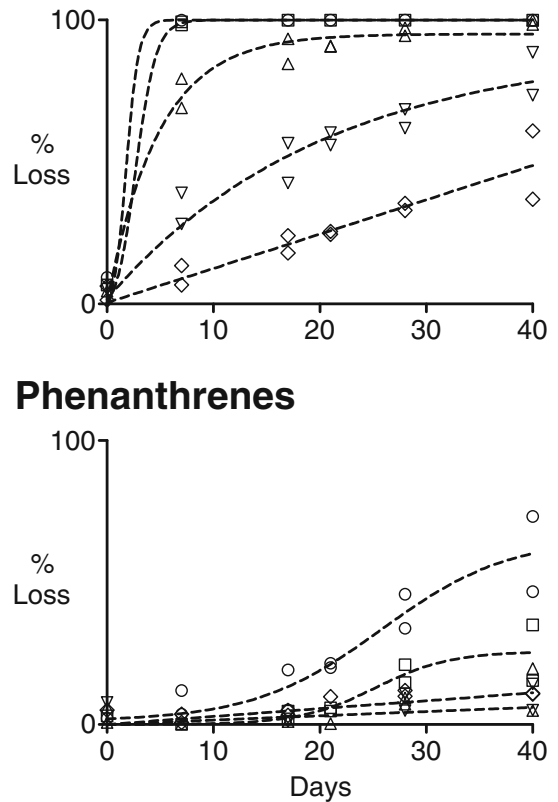

Dispersed
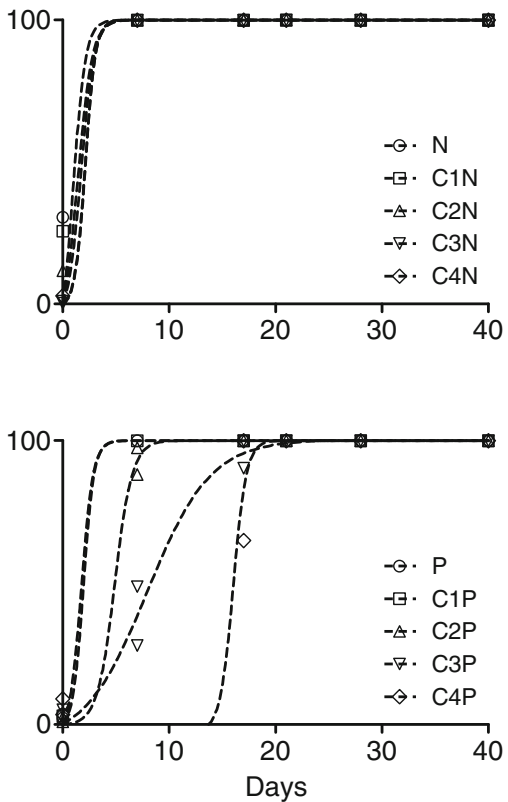


\section{Results}

Figure 2 shows representative chromatograms of oils extracted at the initiation of the experiment (15 min after the assembly of the experiments) and after 7 and 40 days of incubation. The sharp peaks are the $n$ - and branched alkanes, while the broad features are the "unresolved complex mixture" in which reside the polycyclic aromatic hydrocarbons. It is clear that biodegradation and evaporation are occurring in samples with and without dispersant, but it is obvious that biodegradation is far more extensive in the dispersed oil than in the slick. Within a week, the dispersed oil had lost approximately half of its detectable hydrocarbons, while the slick had lost only $14 \%$, and by 40 days, the slick had still not degraded as much as the dispersed oil had in 7 days. Meanwhile, primary biodegradation of the hydrocarbons had reached $84 \%$ in the dispersed oil. Figure 3 shows this graphically, with panel a showing loss of total detectable hydrocarbons, and panel $b$ the loss of the polycyclic aromatic hydrocarbons on the USEPA priority pollutant list (Keith and Telliard 1979). Naphthalene is the most abundant of these molecules in this oil, and the loss of this compound can be attributed to both evaporation and biodegradation (Fig. 4), but its alkyl congeners, and the phenanthrenes, are not significantly volatile, and their disappearance (Fig. 4) can be attributed to biodegradation. Clearly, dispersed oil degraded much more rapidly and extensively than undispersed oil.

\section{Discussion}

As far as we are aware, this is the first laboratory demonstration of a substantial and dramatic stimulation of the rate of biodegradation of crude oil by the addition of an oil dispersant. At first glance, this seems to contradict a substantial body of work that found only minimal stimulation at best (Van Hamme and Ward 1999; Lindstrom and Braddock 2002; Venosa and Holder 2007; Prince et al. 2013). We believe that this can be entirely attributed to the fact that in those experiments the relatively low concentrations of oil dispersed quite naturally, almost as well as with dispersants, albeit with slightly larger droplet size (Shaw and Reidy 1979). Since biodegradation is likely dependent on the surface area available for microbial colonization, there is only a small increase of accessibility in decreasing droplet size once small droplets have formed. In contrast, going from a floating slick to $70 \mu \mathrm{m}$ droplets increases surface area by at least 20 -fold, and the stimulation of biodegradation seen here is consistent with this increase.

Several things are noteworthy. The first is that the biodegradation of dispersed oil in these experiments is only marginally faster than it was in water collected at the same site under winter conditions, an apparent "half-life" of about 1 week at $21{ }^{\circ} \mathrm{C}$ (Fig. 2) compared with 11 days at $8{ }^{\circ} \mathrm{C}$ (Prince et al. 2013), which compares with 28 days (at $100 \mathrm{ppm}$ oil) at $27.5^{\circ} \mathrm{C}$ off the Penang, Malaysia shore (Zahed et al. 2011). The second is that these experiments used fresh seawater, not an acclimated inoculum (Venosa and Holder 2007; Campo et al. 2013), thus allowing the indigenous microbes to respond to the oil with the indigenous levels of biological nitrogen, phosphorus, and iron, etc. Next is the observation that the water under the floating slick in the undispersed experiments contained no detectable hydrocarbons (detection limit of the order of a few parts per billion for individual compounds), indicating that any hydrocarbons that dissolved out of the floating slick were promptly degraded by the indigenous microbes.

Our experiments offer the potential for developing a protocol for assessing the biodegradability of dispersed oil that might reveal differences between the biodegradability of dispersions generated by different dispersants. The tests described in the Introduction already offer a way of comparing the dispersion effectiveness of different commercial and experimental products. Building on our protocol, especially to assess and ensure its precision, might allow the development of tests for assessing whether particular formulations stimulate or transiently inhibit biodegradation (Varadaraj et al. 1995). As the protocol is developed, it will be important to ensure that the stirring is well controlled, since it is well known that mixing energy is a primary determinant of the differences seen in the current tests (Venosa et al. 2002; Clark et al. 2005). We use fresh seawater as inoculum because we do not have a clear idea of how to preserve an inoculum for repeated use. This may introduce variability, but attempts to maintain or preserve cultures also have their difficulties, most notably prolonged lag phases before biodegradation begins (Venosa and Holder 2007). More work is needed to determine the better option.

Open Access This article is distributed under the terms of the Creative Commons Attribution License which permits any use, distribution, and reproduction in any medium, provided the original author(s) and the source are credited.

\section{References}

Baelum J, Borglin S, Chakraborty R, Fortney JL, Lamendella R, Mason OU, Auer M, Zemla M, Bill M, Conrad ME, Malfatti SA, Tringe SG, Holman H, Hazen TC, Jansson JK (2012) Deep-sea bacteria enriched by oil and dispersant from the Deepwater Horizon spill. Environ Microbiol 14:2405-2416

Becker KW, Walsh MA, Fiocco RJ, Curran MT (1993) A new laboratory method for evaluating oil spill dispersants. In Proc 1993 Int. Oil Spill Conf. American Petroleum Institute, Washington, pp 507-510

Belore RC, Trudel K, Mullin JV, Guarino A (2009) Large-scale cold water dispersant effectiveness experiments with Alaskan crude oils and Corexit 9500 and 9527 dispersants. Mar Pollut Bull 58:118-128

Campo P, Venosa AD, Suidan MT (2013) Biodegradability of Corexit 9500 and dispersed South Louisiana crude oil at 5 and $25{ }^{\circ} \mathrm{C}$. Environ Sci Technol 47:1960-1967 
Clark J, Becker K, Venosa A, Lewis A (2005) Assessing dispersant effectiveness for heavy fuel oils using small-scale laboratory tests. In Proc 2005 Int. Oil Spill Conf. American Petroleum Institute, Washington, pp 59-63

Clayton JR, Payne JR, Farlow JS (1993) Oil spill dispersants. Mechanisms of action and laboratory tests. CRC Press, Inc, Boca Raton, p 113

Delvigne GAL (1993) Natural dispersion of oil by different sources of turbulence. In Proc 1993 Int. Oil Spill Conf. American Petroleum Institute, Washington, pp 415-419

Douglas GS, McCarthy KJ, Dahlen DT, Seavey JA, Steinhauer WG, Prince RC, Elmendorf D (1992) The use of hydrocarbon analyses for environmental assessment and remediation. J Soil Contam $1: 197-216$

ExxonMobil Corporation (2013) Alaska North Slope Crude oil. http:// www.exxonmobil.com/crudeoil/about_crudes_ans.aspx (accessed July 24, 2013)

Hazen TC, Dubinsky EA, DeSantis TZ, Andersen GL, Piceno YM, Singh N, Jansson JK, Probst A, Borglin SE, Fortney JL, Stringfellow WT, Bill M, Conrad MS, Tom LM, Chavarria KL, Alusi TR, Lamendella R, Joyner DC, Spier C, Baelum J, Auer M, Zemla ML, Chakraborty R, Sonnenthal EL, D'haeseleer P, Holman HN, Osman S, Lu Z, Van Nostrand JD, Deng Y, Zhou J, Mason OU (2010) Deep sea oil plume enriches indigenous oil-degrading bacteria. Science 330:204-208

Hemmer MJ, Barron MG, Greene RM (2011) Comparative toxicity of eight oil dispersants, Louisiana sweet crude oil (LSC), and chemically dispersed LSC to two aquatic test species. Environ Toxicol Chem 30:2244-2252

Keith LH, Telliard WA (1979) Priority pollutants I-a perspective view. Environ Sci Technol 13:416-423

Lee K, Nedwed T, Prince RC, Palandro D (2013) Lab tests on the biodegradation of chemically dispersed oil should consider the rapid dilution that occurs at sea. Mar Pollut Bull in press (http://dx.doi.org/ 10.1016/j.marpolbul.2013.06.005

Lessard RR, DeMarco G (2000) The significance of oil spill dispersants. Spill Sci Technol Bull 6:59-68

Lindstrom JE, Braddock JF (2002) Biodegradation of petroleum hydrocarbons at low temperature in the presence of the dispersant Corexit 9500. Mar Pollut Bull 44:739-747

Louanchi F, Najjar RG (2001) Annual cycles of nutrients and oxygen in the upper layers of the North Atlantic Ocean. Deep Sea Res II 48:2155-2171

Li Z, Lee K, King T, Boufadel MC, Venosa AD (2009) Evaluating crude oil chemical dispersion efficacy in a flow-through wave tank under regular non-breaking wave and breaking wave conditions. Mar Pollut Bull 58:735-744

Mackay D, Nadeau JS, Ng C (1978) A small-scale laboratory dispersant effectiveness test. In: McCarthy LT, Lindblom GP, Walter HF (eds)
Chemical dispersants for the control of oil spills. ASTM Press, Philadelphia, pp 35-49

MacNaughton SJ, Swannell R, Daniel F, Bristow L (2003) Biodegradation of dispersed Forties crude and Alaskan North Slope oils in microcosms under simulated marine conditions. Spill Sci Technol Bull 8:179-186

Martinelli FM (1984) The status of the warren spring Laboratory's rolling flask test. In: Allan TE (ed) Oil spill chemical dispersants: research, experience, and recommendations. ASTM Press, Philadelphia, pp $55-68$

National Research Council (1989) Using oil spill dispersants on the sea. National Academy of Science, Washington

National Research Council (2005) Understanding oil spill dispersants: efficacy and effects. National Academy of Science, Washington

Prince RC (2010) Eukaryotic hydrocarbon degraders. In: Timmis KN (ed) Handbook of hydrocarbon and lipid microbiology. Springer, Berlin, pp 2066-2078

Prince RC, Elmendorf DL, Lute JR, Hsu CS, Haith CE, Senius JD, Dechert GJ, Douglas GS, Butler EL (1994) $17 \alpha(\mathrm{H}), 21 \beta(\mathrm{H})$-hopane as a conserved internal marker for estimating the biodegradation of crude oil. Environ Sci Technol 28:142-145

Prince RC, Gramain A, McGenity TJ (2010) Prokaryotic hydrocarbon degraders. In: Timmis KN (ed) Handbook of hydrocarbon and lipid microbiology. Springer, Berlin, pp 1672-1692

Prince RC, McFarlin KM, Butler JD, Febbo EJ, Wang FC, Nedwed TJ (2013) The primary biodegradation of dispersed crude oil in the sea. Chemosphere 90:521-526

Shaw DG, Reidy SK (1979) Chemical and size fractionation of aqueous petroleum dispersions. Environ Sci Technol 13:1259-1263

Van Hamme JD, Ward OP (1999) Influence of chemical surfactants on the biodegradation of crude oil by a mixed bacterial culture. Can J Microbiol 45:130-137

Varadaraj R, Robbins ML, Bock J, Pace S, MacDonald D (1995) Dispersion and biodegradation of oil spills on water. In Proc 1995 Int Oil Spill Conf. American Petroleum Institute, Washington, pp 101-106

Venosa AD, Holder EL (2007) Biodegradability of dispersed crude oil at two different temperatures. Mar Pollut Bull 54:545-553

Venosa AD, Holder EL (2012) Determining the dispersibility of South Louisiana crude oil by eight oil dispersant products listed on the NCP product schedule. Mar Pollut Bull 66:73-77

Venosa AD, King DW, Sorial GA (2002) The baffled flask test for dispersant effectiveness: a round robin evaluation of reproducibility and repeatability. Spill Sci Technol Bull 7:299-308

Zahed MA, Aziz HA, Isa MH, Mohajeri L, Mohajeri S, Kutty SRM (2011) Kinetic modeling and half-life study on bioremediation of crude oil dispersed by Corexit 9500. J Hazard Mater 185:10271031 